\title{
Protocatechualdehyde Induces Apoptosis in Human Non-Small-Cell Lung Cancer Cells by up Regulation of Growth Arrest and DNA Damage- Inducible (GADD) Genes
}

\author{
Satyajit Patra ${ }^{1 *}$, Roshan Mascarenhas ${ }^{2}$, Naseer Maliyakkal ${ }^{3}$ and Jesil Mathew Aranjani ${ }^{4}$ \\ ${ }^{1}$ Department of Pharmacology, Medical University of the Americas, Nevis, West Indies \\ ${ }^{2}$ Department of Molecular and Cellular Biochemistry, The Ohio State University, Columbus, OH 43210, USA \\ ${ }^{3}$ Manipal College of Pharmaceutical Sciences, Manipal University, Manipal, India 576104 \\ ${ }^{4}$ Department of Pharmaceutical biotechnology, Manipal College of Pharmaceutical Sciences, Manipal, India
}

\begin{abstract}
Growth arrest and DNA damage-inducible (GADD) 45 and GADD153 proteins have been implicated in DNA repair, cell cycle regulation and growth arrest along with numerous other cellular mechanisms. In recent years, evidence has emerged that proteins encoded by these genes play pivotal roles in tumor suppression and apoptotic cell death. Thus, compounds altering the expression of these genes are likely to be of interest in cancer prevention and/or treatment. Protocatechualdehyde is isolated from Phellinus gilvus and has been investigated as a promising cancer preventive agent because of its medicinal properties. This mushroom belongs to Hymenochaetaceae Basidiomycetes, and has advantages over many Phellinus species due to short growth period ( 3 months), making production cost-effective. The exact molecular mechanisms of protocatechualdehyde are not clearly understood. Based on studies of pro-apoptotic activity of protocatechualdehyde in T-cells and colorectal cancer cells, we examined the relationship between the expression of GADD45 and GADD153 and apoptosis induction in human lung cancer cell line PC-9. We report a p ${ }^{53}$ independent increase in GADD45 and GADD153 expression by protocatechualdehyde. Likewise, the proliferation of PC-9 cells is inhibited via a G1/S arrest of the cell-cycle stimulating apoptosis. Further, induction of apoptosis was inhibited in PC-9 cells knocked down for GADD45 and GADD153. Protocatechualdehyde treatment also induced the expression of cell cycle inhibitors $\mathrm{p}^{21}$ and $\mathrm{p}^{27}$, while inhibiting Bcl-2, cyclin D1, CDK2, CDK4 and CDK6 genes. These findings suggest that upregulation of GADD45 and GADD153 proteins are the mechanism for protocatechualdehyde's anti-tumor activities.
\end{abstract}

Keywords: Protocatechualdehyde; Apoptosis; Cell-cycle; Lung cancer; Cancer prevention

\section{Introduction}

Growth arrest and DNA damage-inducible (GADD) 45 and GADD153 proteins have been implicated in DNA repair, cell cycle regulation and growth arrest along with numerous other cellular mechanisms. In recent years, evidence has emerged that proteins encoded by these genes play pivotal roles in tumor suppression and apoptotic cell death. The GADD45 expression is rapidly regulated at both transcriptional and post-transcriptional levels in response to genotoxic stress via $\mathrm{p}^{53}$ tumor suppressor pathway or by mRNA stability as well as other growth-arrest signals [1]. Several studies have correlated GADD153 expression with cell death by treating the cells to different stress conditions especially with DNA damaging agents. Because of the involvement of GADD45 protein with the cell cycle, apoptosis, DNA repair and stability makes it an obvious target for cancer therapy [2]. Previous studies show that GADD45 and GADD153 proteins play key roles in the induction of programmed cell death and thus we sought to investigate their role in human lung cancer. In this study two GADD genes (GADD45 and GADD153) were studied representing a $\mathrm{p}^{53}$ dependent and a $\mathrm{p}^{53}$-independent pathway respectively.

Lung cancers are carcinomas that derive from epithelial cells with small-cell lung carcinoma (SCLC), and non-small-cell lung carcinoma (NSCLC) being the main types. The estimated deaths from lung cancer is 159,480 (87,260 in men and 72,220 among women), accounting for about $27 \%$ of all cancer deaths [3]. Worldwide, there are 2.28 million new cases of lung cancer annually, with 1.59 million deaths, making lung cancer a leading cause of cancer-related mortality and account for an estimate of about $14 \%$ of all new cancers [4]. Tobacco use, particularly of smoking, is the main contributor to lung cancer; however, a significant number of non-smoking individuals are reported with lung cancer [5]. Males show higher mortality rate because of increased risk of lung cancer associated with cigarette smoking [6] approximately reporting 63,000 new lung cancer cases each year in India [7]. Impediment in early detection and diagnosis of advanced stage is the main reason for high mortality [8]. The best strategy is to minimize the development of lung cancer using cancer preventive agents. There is a strong interest in cancer prevention with widely investigated natural products, such as capsaicin, green tea, turmeric, cardamom and resveratrol.

Protocatechualdehyde which is isolated from Phellinus gilvus, has been investigated as a promising cancer preventive agent because of its medicinal properties. This mushroom belongs to Hymenochaetaceae Basidiomycetes, and has advantages over many Phellinus species due to short growth period (3months), making production costeffective [9-11]. Previous studies have established various biological activities of protocatechualdehyde. Among the reported benefits of protocatechualdehyde are inhibition of pulmonary inflammation, prevention of intraperitoneal adhesion under infectious circumstances, promotion of dermal wound healing, anti-platelet aggregation and antitumor activities $[9,10,12,13]$. Protocatechualdehyde has been

*Corresponding author: Satyajit Patra, Department of Pharmacology, Medical University of the Americas, Nevis, West Indies, Tel: +1 869-469-9177; Fax: +1 869-469-9180; E-mail: s.patra@mua.edu

Received September 18, 2013; Accepted October 18, 2013; Published October 25, 2013

Citation: Patra S, Mascarenhas R, Maliyakkal N, Aranjani JM (2013) Protocatechualdehyde Induces Apoptosis in Human Non-Small-Cell Lung Cance Cells by up Regulation of Growth Arrest and DNA Damage-Inducible (GADD) Genes. Mol Biol 2: 113. doi:10.4172/2168-9547.1000113

Copyright: ( 2013 Patra S, et al. This is an open-access article distributed under the terms of the Creative Commons Attribution License, which permits unrestricted use, distribution, and reproduction in any medium, provided the original author and source are credited. 
a subject of continuous interest because of its effective scavenging property for oxygen free radicals [14,15]. DPPH (2,2-diphenyl-1picrylhydrazyl) free radical scavenging and xanthine-oxidase (XO)inhibitory activities, antioxidant/anti-inflammatory activities of protocatechualdehyde have been evaluated. Apoptotic cell death induced by protocatechualdehyde is demonstrated in different cells. The exact molecular mechanisms of protocatechualdehyde are not clearly understood [16-19]. Since protocatechualdehyde is well studied to have therapeutic effects on various types of diseases, the cancer preventive activity of protocatechualdehyde is of very much interest, and experiments with protocatechualdehyde in animal models indicate the protective nature against several diseases. Specifically, protocatechualdehyde inhibited cell growth of various cancer cell lines, and induced apoptosis of cancer cells [16,20-22]. Moreover, protocatechualdehyde was shown effective on cell-cycle regulation of the mammalian cell line [17]. Based on these findings, we investigated the molecular mechanisms of cancer preventive and anti-cancer activities of protocatechualdehyde for lung cancer prevention in humans, and this study provides the first report on role of protocatechualdehyde in the prevention of lung cancer in human.

Numerous reports have focused on evidence that the cancer preventive activity is stimulated by altering the phases of cell cycle, associated with the modulation of their regulatory components [23,24]. This suggests that these genes are induced by stimulation of GADD45 and GADD153 in response to DNA damage and growth arrest, which is shown in many cell types. In this study we report the anti-proliferative effects of protocatechualdehyde on human lung cancer cell lines PC-9 and A549 by inducing GADD45 and GADD153 by $\mathrm{p}^{53}$ independent manner. These results add to our knowledge on importance of protocatechualdehyde on lung cancer prevention.

\section{Materials and Methods}

\section{Chemicals and reagents}

Protocatechualdehyde, 4', 6-diamidino-2-phenylindole (DAPI), and propidium iodide (PI) were purchased from Sigma-Aldrich Pvt. Ltd. (India). Antibodies specific for GADD45, GADD153 and GAPDH were obtained (Santa Cruz Biotechnology, Santa Cruz, CA).

\section{Cell culture and transfection}

The human non-small cell lung cancer cell lines A549 and PC-9 were cultured in DMEM-F12 supplemented with 10\% HyClone fetal bovine serum (FBS) (ThermoFisher Scientific, Fremont, CA, USA) in an atmosphere of $5 \% \mathrm{CO} 2$ at $37^{\circ} \mathrm{C}$. Cells were grown in $75 \mathrm{~cm}^{2}$ culture flasks and harvested in a solution of trypsin-EDTA at the logarithmic growth phase.

PC-9 cells were transfected with human GADD45 and GADD153 specific siRNAs prepared by Invitrogen. Stealth RNAi negative control duplex (Invitrogen) was used as a control. The siRNA targeting GADD45 corresponds to the sequence GAGCAGAAGACCGAAAGGAUGGAUA, and the siRNA targeting GADD153 corresponds to the sequence GAGAAUGAACGGCUCAAGCAGGAAA. PC-9 cells were transfected using Lipofectamine RNAi max (Invitrogen), according to manufacturer's instruction. In brief, $1.4 \times 10^{6} \mathrm{PC}-9$ cells were transfected with final concentration of $50 \mathrm{nM}$ siRNA in six-well culture plate in triplicates. Cells were treated with protocatechualdehyde or vehicle $24 \mathrm{~h}$ after transfection. DAPI staining was performed for apoptosis assay. Cells were lysed in lysis buffer containing $0.2 \% \mathrm{NP}$ 40. Total RNA was extracted from the cells lysate using TRIzol reagent following the manufacturer's instructions (Invitrogen).

\section{Western blotting}

Cells lysate was estimated for total protein content by Bradford assay. Total $10 \mu \mathrm{g}$ of protein sample was run on $10 \%$ polyacrylamide gel. Subsequently transferred to a polyvinylidene difluoride (PVDF) (Millipore) membrane by semi-dry electroblotting. Blocked in 5\% nonfat dry milk in TBS with Tween $20(0.05 \%)$. Blots were incubated at RT for $1 \mathrm{~h}$ in primary antibody at 1:1250 dilutions in blocking solution. Following washing with TBST, membranes were incubated respective horseradish peroxidase (HRP)-conjugated secondary antibody, and visualized with ECL plus western blot detection kit (GE Healthcare).

\section{Cell viability and cell growth assay}

Trypan blue dye exclusion method: PC-9 cells $\left(1 \times 10^{4} / \mathrm{ml}\right)$ were cultured in 6-well plates for $24 \mathrm{~h}$ followed by treatment with different concentrations of protocatechualdehyde or vehicle as control supplemented with $10 \%$ FBS for 24-72 h with changing culture medium every $24 \mathrm{~h}$. Protocatechualdehyde was dissolved in DMSO as stock solution and stored at $-20^{\circ} \mathrm{C}$. Trypan blue dye exclusion test [25] was used to determine the inhibition of cell growth. The result was expressed as a percentage, relative to treatment with vehicle control, and the $\mathrm{IC}_{50}$ values were calculated using non-linear regression analysis (percent survival versus concentration). Results shown are from at least three independent experiments performed in replicates.

MTT assay: Cell viability was evaluated by measuring the amount of insoluble formazan formed in live cells based on the reduction of MTT salt. Briefly, $100 \mu \mathrm{l} \mathrm{PC-9}$ cell suspensions at $2 \times 10^{4} \mathrm{cell} / \mathrm{ml}$ were seeded in 96 well micro titer plate (BD, USA). Protocatechualdehyde in concentration range of $0-100 \mu \mathrm{g} / \mathrm{ml}$ were added. MTT reagent was added after $72 \mathrm{~h}$ exposure followed by dissolution of formed formazan crystal using DMSO (Sigma, USA). Optical density was read with ELISA reader (LX-800) at $550 \mathrm{~nm}$. The dose-response curve is plotted and concentration that exhibited $50 \%$ inhibition of cell growth $\left(\mathrm{IC}_{50}\right)$ is calculated. Concentration that inhibits $50 \%$ of cell viability was used as a parameter for cytotoxicity.

\section{Cell-cycle analysis}

To compare the effects of different concentration of protocatechualdehyde on the cell cycle, the Cycle TEST ${ }^{\text {max }}$ PLUS DNA Reagent Kit (Becton Dickinson, USA) was used. The cells $\left(1 \times 10^{6}\right.$ cells/ $\mathrm{ml}$ ) were seeded in a 6-well plate and treated with protocatechualdehyde for $24 \mathrm{~h}$. After harvesting, made to suspension, permeabilized with trypsin buffer. Incubated with propidium iodide $(1 \mathrm{mg} / \mathrm{ml})$ for $10 \mathrm{~min}$ in dark. Cells were analyzed by flow cytometry (BD FACS Calibur, USA) using BD Cell Quest acquisition and analysis software. Cell cycle phase distribution of nuclear DNA was determined by analyzing at least 10,000 cells per sample and the percentage of cells in G1, S and G2 phases.

\section{Apoptosis assay}

Identification and quantitation of apoptotic cells were done by DAPI staining. PC- 9 cells were cultured overnight at the density of 5 $\times 10^{5}$ cells $/ \mathrm{ml}$ in a 6-well culture plate and then treated with different concentrations $(0-100 \mu \mathrm{g} / \mathrm{ml})$ of protocatechualdehyde for $24 \mathrm{~h}$. The cells were then fixed with $500 \mu \mathrm{L}$ fixing solution (acetic acid: methanol; 1:3) for $5 \mathrm{~min}$, dried, and stained with the DNA-specific fluorochrome DAPI $(2 \mu \mathrm{g} / \mathrm{ml})$. Following 10 min of incubation, the cells were washed with phosphate buffered saline (PBS), air-dried, mounted with $90 \%$ (v/v) glycerol. The percentage of apoptotic cells was calculated using fluorescence microscopy (Olympus, Japan) with at least 200 randomly selected cells. Results are obtained from at least three independent experiments. 
Quantitation of cell cycle and apoptosis related gene expression by Quantitative Real-Time Polymerase Chain Reaction (qRT-PCR)

Total RNA was extracted from cultured PC-9 cells treated with various concentrations of protocatechualdehyde for $24 \mathrm{~h}$ using the TRIzol reagent and then one $\mu \mathrm{g}$ of RNA subjected to reversetranscription using SuperScript ${ }^{\bullet}$ III First-Strand Synthesis System (Life Technologies, Inc.). To allow a quantitative determination of relative gene expression levels for the apoptosis related genes [26]. The cDNA content of the samples was normalized, and the linear range of amplification was determined using SYBR Green reagent for each primer set PCR on 7300 Real Time PCR System (Applied Biosystems). GAPDH expression was used as normalization control. At least two independent experiments were performed to confirm the results. The sequences of the primers used are provided in Table 1.

\section{Statistical analysis}

Statistical analyses were performed with Student's $t$-test. The results were considered to be significant when $p$ value was less than 0.05 , ${ }^{*} p<0.05,{ }^{*} p<0.01$.

\section{Results}

Effects of protocatechualdehyde exposure on cell viability and cell growth

Protocatechualdehyde inhibited cell growth in PC-9 cells, when exposed with various concentrations and the inhibition was dosedependent manner shown in Figure 1. After $24 \mathrm{~h}$ treatment with 100 $\mu \mathrm{M}$ protocatechualdehyde, the percentage of viable cells was $47.3 \%$ of the vehicle control and after $48 \mathrm{~h}$ treatment with 75 and $100 \mu \mathrm{M}$ protocatechualdehyde viable cells reduced to 48.6 and $31.0 \%$ of control. The lowest and highest dose with significant changes were observed at $50 \mu \mathrm{M}$ and $100 \mu \mathrm{M}$ respectively, above which no considerable changes were observed and therefore these two doses were used in the study for analysis of role of protocatechualdehyde on expression of gene of interest.

\section{Protocatechualdehyde induce apoptosis of PC-9 Cells}

We determined the mechanisms of growth inhibition activity of PC-9 cell lines and further investigated apoptosis of PC-9 cells by morphological changes with DAPI staining. Cells were treated with various concentrations of protocatechualdehyde and percentage of apoptotic cells increased dose-dependent manner and cells with condensed and fragmented nuclei were observed. After $48 \mathrm{~h}$ treatment of cells with protocatechualdehyde at 25, 50, 75 and $100 \mu \mathrm{M}$ concentrations, apoptosis was induced as $11.4,32.5,41.5$ and $62.3 \%$ of cells respectively (Figure 2). From the above results it was confirmed that protocatechualdehyde treated cells shows alterations in the expression of GADD genes, growth inhibition, and stimulation of cell cycle arrest and apoptosis.

\section{Effect of protocatechualdehyde on cell cycle regulation in} PC-9 Cells

Regulatory effects of protocatechualdehyde on the cell cycle were evaluated in PC-9 cells. Protocatechualdehyde at a concentration of $100 \mu \mathrm{M}$ in PC-9 cells significantly increased the cells of G1 phase from 46.6 to $63.2 \%$ (Figure 3, Table 2). PC-9 cells when treated with protocatechualdehyde at concentrations of 25 and $50 \mu \mathrm{M}$ for $24 \mathrm{~h}$, an accumulation of $S$ phase respectively was observed (Figure 3 , Table 2).The growth inhibition was linked to protocatechualdehyde induced G1 and S phase arrests in the cell cycle in PC-9 cells.
Protocatechualdehyde induced expression of genes associated with cell cycle and apoptosis

The eukaryotic cell cycle is regulated by the periodic synthesis and destruction of cyclins and their cyclin-dependent kinases and

\begin{tabular}{|c|c|c|}
\hline Gene & Sequence Forward (5'-3') & Sequence Reverse (5'-3') \\
\hline GAPDH & CCAGCAAGAGCACAAGAGGA & TACATGACAAGGTGCGGCTCCC \\
\hline $\mathrm{BCl}-2$ & CTGCACCTGACGCCCTTCACC & CACATGACCCCACCGAACTCAAAGA \\
\hline Bax & TCAGGATGCGTCCACCAAGAAG & TGTGTCCACGGCGGCAATCATC \\
\hline Cyclin D1 & AGCTCCTGTGCTGCGAAGTGGAAAC & AGTGTTCAATGAAATCGTGCGGGGT \\
\hline$C D K 2$ & ATGGATGCCTCTGCTCTCACTG & CCCGATGAGAATGGCAGAAAGC \\
\hline$C D K 4$ & CCATCAGCACAGTTCGTGAGGT & TCAGTTCGGGATGTGGCACAGA \\
\hline CDK6 & ACCTCTGGAGTGTCGGTTGCAT & TTCCTCTCCTGGGAGTCCAATG \\
\hline GADD45 & GCCTGTGAGTGAGTGCAGAA & ССССАССТТАТССАТССТТТ \\
\hline GADD153 & AGAACCAGGAAACGGAAACAGA & TCTCCTTCATGCGCTGCTTT \\
\hline$p 21$ & GGCAGACCAGCATGACAGATT & GCGGATTAGGGCTTCCTCT \\
\hline p27 & AGGAGAGCCAGGATGTCAGC & CAGAGTTTGCCTGAGACCCAA \\
\hline
\end{tabular}

Table 1: Primer sequences Used in Quantitative Real-Time PCR.

Growth Inhibition

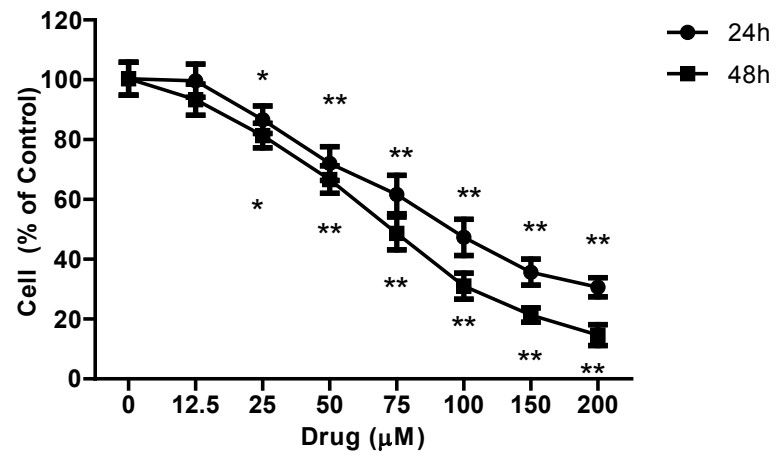

Figure 1: Effects of protocatechualdehyde exposure on cell viability and cell growth: Effects of protocatechualdehyde on cell viability in PC-9 cell lines was tested by treating with increasing concentrations of protocatechualdehyde for 24 and 48 hours. The viable cell numbers were counted using a hemocytometer via trypan blue dye exclusion. Values are expressed as means \pm SD of three separate experiments performed in triplicate. ${ }^{*} p<0.05$. ${ }^{* *} p<0.01 . a$.

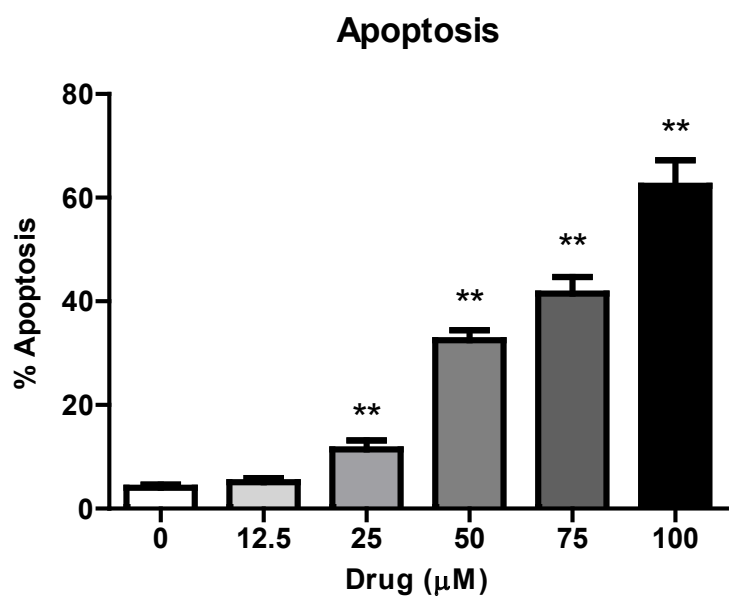

Figure 2: Protocatechualdehyde induce apoptosis of PC-9 Cells: Apoptotic cells were counted in PC-9 cells randomly after DAPI staining and morphological changes showing apoptosis features were measured by fluorescence microscopy. Results of three independent experiments $( \pm S D$ ) shown as apoptotic index. ${ }^{* *} \mathrm{p}<0.01$. 


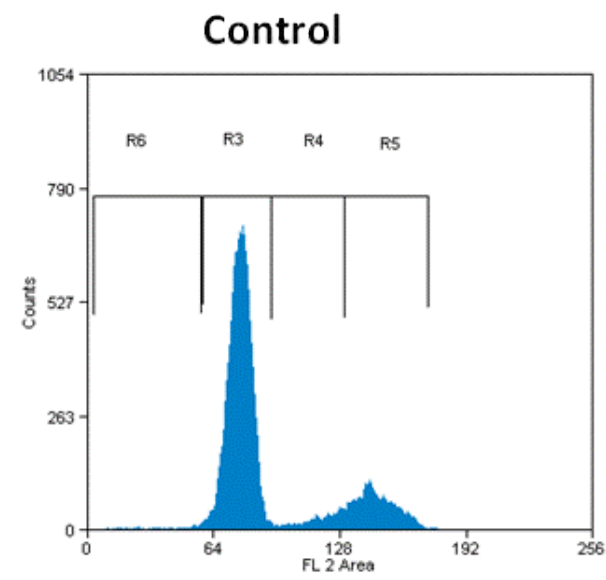

$50 \mu \mathrm{M}$

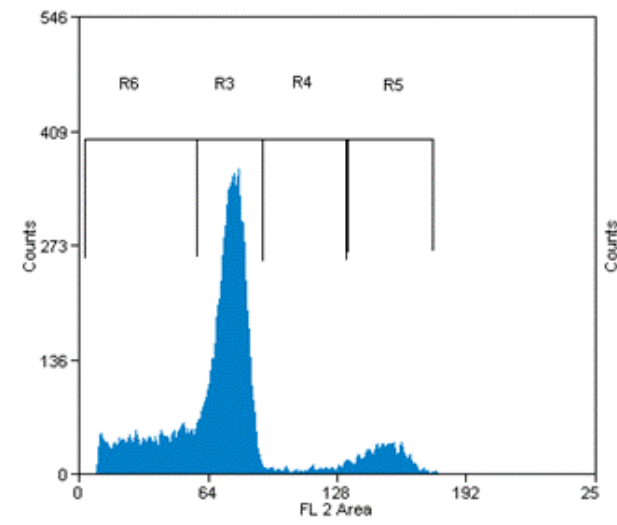

$12.5 \mu \mathrm{M}$

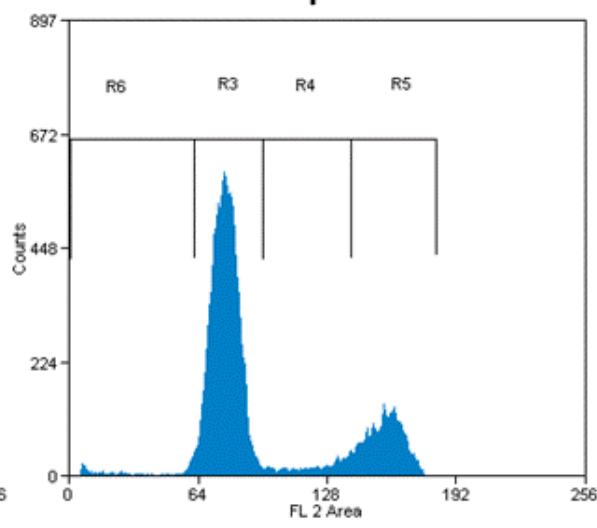

$75 \mu \mathrm{M}$

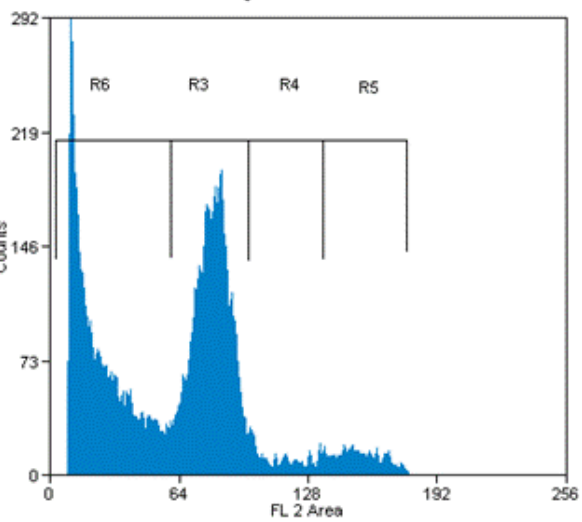

$25 \mu \mathrm{M}$

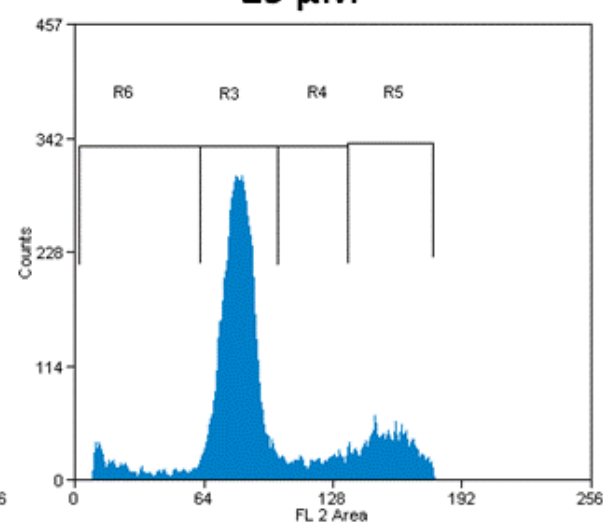

$100 \mu \mathrm{M}$

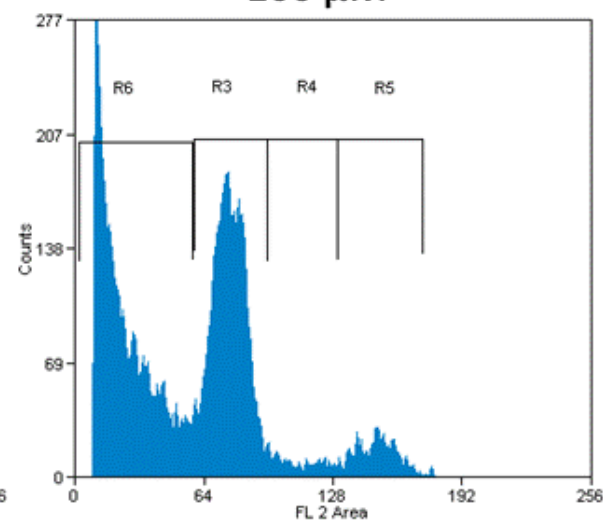

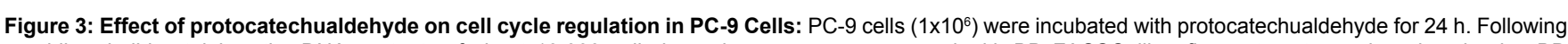
propidium iodide staining, the DNA contents of about 10,000 cells in each group were measured with BD FACSCalibur flow cytometer and analyzed using BD CellQuest software. Similar results were obtained in two independent experiments.

\begin{tabular}{|c|c|c|c|c|}
\hline \multirow{2}{*}{ Protocatechualdehyde $(\mu \mathrm{M})$} & \multicolumn{4}{|c|}{ Cell Cycle Phase } \\
\hline & $\mathrm{G}_{0} / \mathrm{G}_{1}$ & $\mathrm{~S}$ & $\mathrm{G}_{2} / \mathrm{M}$ & Sub $G_{0}$ \\
\hline 0 & $74.2 \pm 2.6$ & $6.4 \pm 0.9$ & $18.6 \pm 1.4$ & $1.2 \pm 0.2$ \\
\hline 12.5 & $71.8 \pm 2.4$ & $5.6 \pm 0.6$ & $21.1 \pm 2.1$ & $2.5 \pm 0.6$ \\
\hline 25 & $67.5 \pm 2.7$ & $8.2 \pm 1.1$ & $17.8 \pm 1.9$ & $7.2 \pm 1.0$ \\
\hline 50 & $65.9 \pm 3.6$ & $2.5 \pm 0.4$ & $9.6 \pm 0.8$ & $22.5 \pm 4.1$ \\
\hline 75 & $46.5 \pm 2.3$ & $4.8 \pm 0.9$ & $5.8 \pm 0.6$ & $43.6 \pm 3.8$ \\
\hline 100 & $41.6 \pm 3.2$ & $3.5 \pm 0.2$ & $6.5 \pm 1.3$ & $48.4 \pm 1.9$ \\
\hline
\end{tabular}

Table 2: Induction of G1/S Cell-Cycle Arrest by Protocatechualdehyde.

negatively controlled by cyclin-dependent kinases inhibitors (called CDIs) [27]. Expressions of these cell-cycle regulatory genes like Cyclin $D 1, C D K 2, C D K 4$ and $C D K 6$ were determined in protocatechualdehyde treated PC-9 cells for understanding the mechanisms of apoptosis. Expression of genes and fold changes were evaluated by quantitative real-time PCR after $24 \mathrm{~h}$ of treatment with protocatechualdehyde in PC-9 cells. Transcript levels of cyclin D1, CDK2, CDK4 and CDK6 genes found to be decreased, as shown in Figure 4. In particular, after $24 \mathrm{~h}$ protocatechualdehyde at $100 \mu \mathrm{M}$ concentration, the mRNA levels of cyclin D1,CDK2, CDK4 and CDK6 were down-regulated 0.28, 0.31, 0.42 and 0.61 fold, compared with that of vehicle control. However, after $24 \mathrm{~h}$ treatment of protocatechualdehyde at a concentration of $100 \mu \mathrm{M}$ significantly increased the mRNA levels of the CDK inhibitors $p^{21}$ and $p^{27}$ to 17.46 and 5.96 fold (Figure 4). Protocatechualdehyde in
PC-9 cells decreased the expression of $B c l-2$ (Figure 4) and there was no change in expression of Bax gene.

\section{Protocatechualdehyde induces GADD45 and GADD153 gene expression}

GADD45 and GADD153 genes were up regulated with protocatechualdehyde treatment in PC-9 cell line. Though the increased expression was time and dose dependent still $100 \mu \mathrm{M}$ protocatechualdehyde dosages increased 29.2 and 21.6 fold expression after $24 \mathrm{~h}$ incubation (Figure 5). Protocatechualdehyde treated human lung cancer cells A549 cells with wild type $\mathrm{p}^{53}$ also showed similar increased expression of GADD45 and GADD153. These results suggest $\mathrm{p}^{53}$-independent induction of GADD45 and GADD153 by protocatechualdehyde. Above observation was confirmed at protein 
Cyclin D1

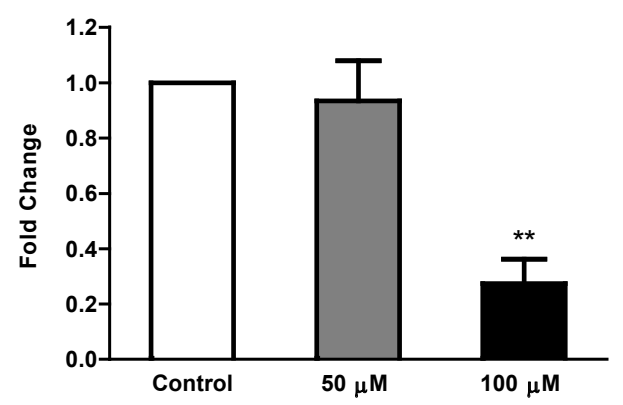

CDK2/CDK4/CDK6

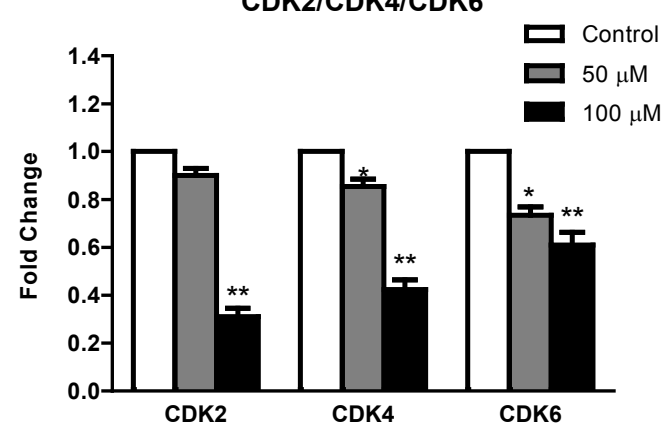

p21

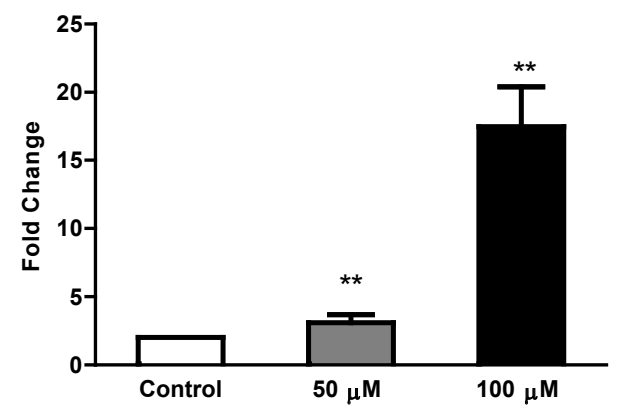

p27

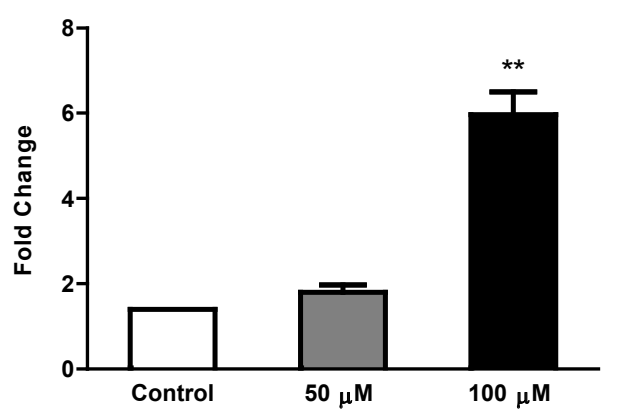

Bcl-2

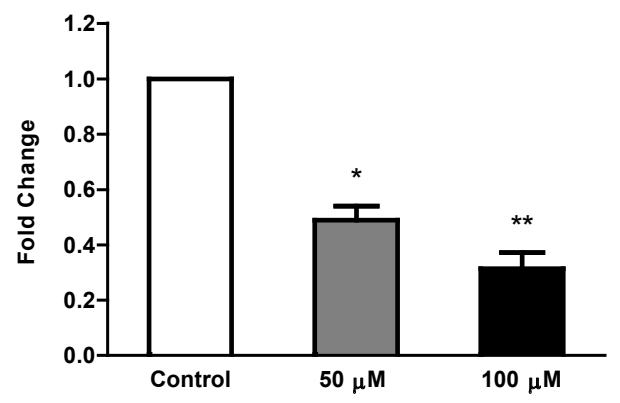

Figure 4: Protocatechualdehyde induced expression of genes associated with cell cycle and apoptosis: Expression levels of genes associated with cell cycle and apoptosis were compared among protocatechualdehyde treated PC-9 cells, by using qRT-PCR. The data are fold difference of the gene expression of two representative experiments performed in triplicate. ${ }^{*} p<0.05,{ }^{* *} p<0.01$. Gene expression levels are normalized to GAPDH of control cells, and taken as 1.

level by western blotting for GADD45 and GADD153 proteins and shown increase in protein level as shown in Figure 5.

\section{Protocatechualdehyde on GADD45 and GADD153 knockdown:}

From the above observations it was clear that protocatechualdehyde induces the GADD45 and GADD153 gene expression with consequential in apoptotic induction. Functions and involvement of GADD45 and GADD153 genes were explored to study the mechanisms of apoptotic induction using siRNA-mediated knockdown of GADD45 and GADD153. PC-9 cells were treated with GADD45 and GADD153 siRNAs for $24 \mathrm{~h}$, and expressions of the GADD45 and GADD153 genes that were induced by $100 \mu \mathrm{M}$ protocatechualdehyde was inhibited (Figure 6A). Furthermore, protein production of GADD45 and GADD153 in PC-9 cells induced by protocatechualdehyde (was also inhibited by the siRNAs (Figure 6B). It was apparent to study the relationship between the reduction of GADD 45 and GADD 153 proteins and its effect on the apoptotic induction by protocatechualdehyde in PC-9 cells. 
GADD45

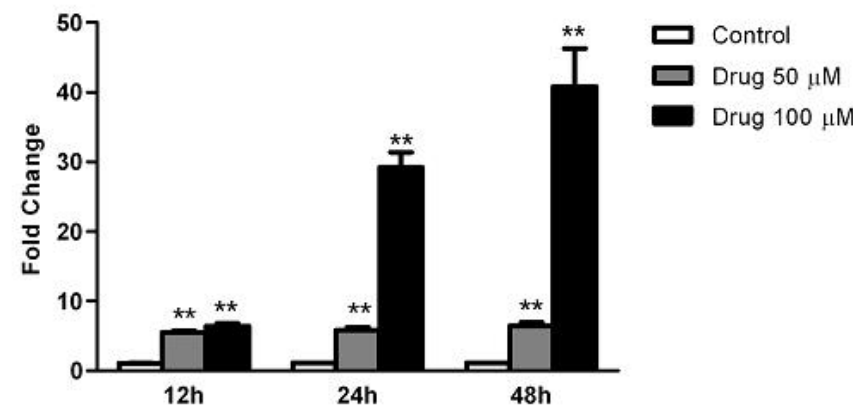

A549

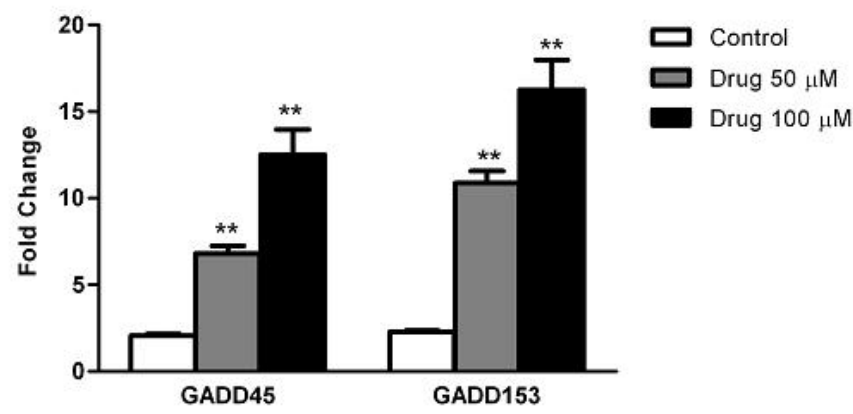

GADD153
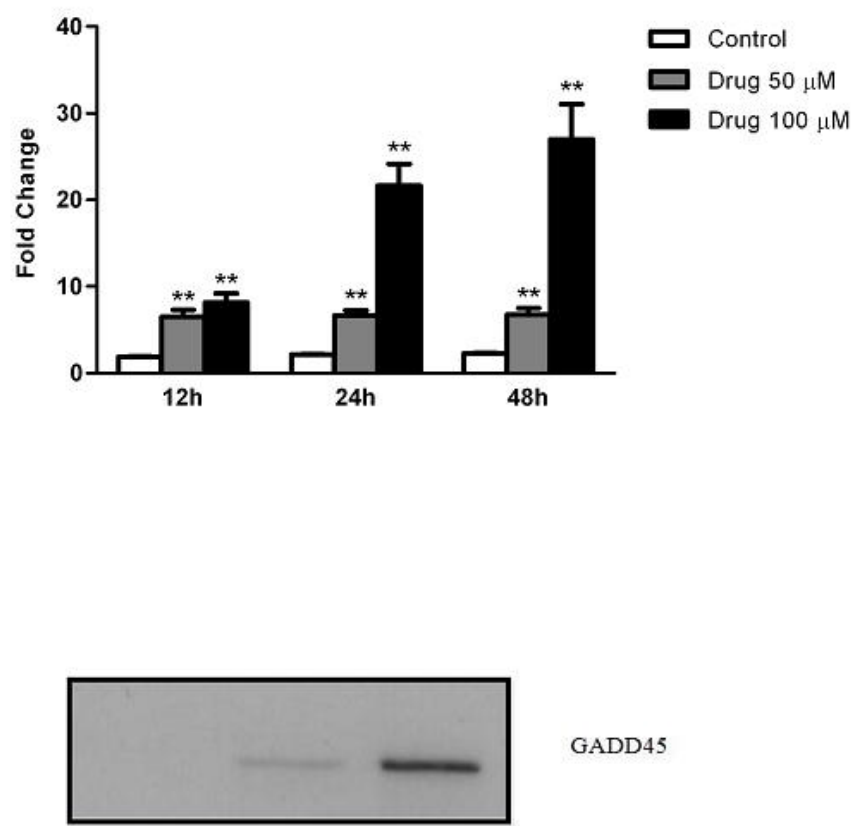

GADD45

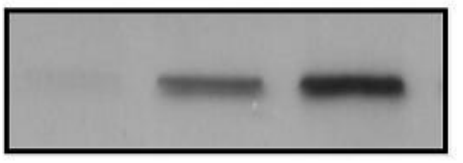

GADD153

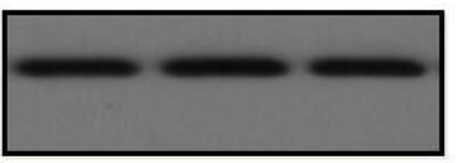

50

100

Figure 5: Protocatechualdehyde induces GADD45 and 153 gene expression: $P C-9$ cells were induced by treating with protocatechualdehyde ( 50 or $100 \mu M$ ) or the same volume of vehicle and then total RNA was harvested and used for gene expression by RT-qPCR performed. The results were analyzed by the delta-Ct method and expression of target genes was normalized to GAPDH expression. Data is presented as fold change to vehicle treated control cells. (**) indicates significant increase, $p<0.05$, in comparison to control. Bars represent mean \pm S.D. of two experiments performed in triplicate. Western blot showing increase in GADD45 and GADD153 protein expression upon treatment, GAPDH served as the loading control.

In comparison with the control experiments where the percentage of apoptotic cells were 20.0 and $33.0 \%$, siRNA induced apoptosis in 24.0 and $35.6 \%$ of PC-9 cells treated with 50 and $100 \mu \mathrm{M}$ protocatechualdehyde, respectively, at $24 \mathrm{~h}$ (Figure 6C). However, PC-9 cells treated with GADD45 and GADD153 siRNA, showed significantly lower sensitivity towards the apoptotic induction by protocatechualdehyde: 11.0 and $11.8 \%$ at $50 \mu \mathrm{M}$, and 15.6 and $16.2 \%$ at $100 \mu \mathrm{M}$, respectively (Figure 6C). From the above observations it was evident that, both the GADD45 and GADD153 genes play significant role in protocatechualdehyde-induced apoptosis and shall be targeted for controlling the apoptosis process in the PC-9 cells.

\section{Discussion}

In the present study, we determined the growth inhibitory activities and $\mathrm{IC}_{50}$ values of protocatechualdehyde and induction of G1/S phase cell cycle arrest and apoptosis in colon cancer PC-9 cells. Earlier studies revealed that protocatechualdehyde was able to exert consistent antiproliferative activity indicating arrest from $G 1$ to $S$ in various cancer cells, such as human colorectal cancer cells and smooth muscle cells
$[16,28]$. The G1/S checkpoint is primarily controlled by collective kinase activities of the complex of cyclin D with CDK4, CDK6 and cyclin $\mathrm{E}$ and these G1 kinases can in turn be regulated by cell cycle inhibitors, which may cause the cells to arrest at the G1 phase [29]. To evaluate the cell cycle inhibitor effect of protocatechualdehyde, we investigated changes in regulation of putative G1 cyclin such as cyclin $D 1$ and the cyclin dependent kinase $C D K 2, C D K 4, C D K 6$ and observed that cell-cycle arrest is associated with downregulation of these cell cycle regulators [30]. Nuclear protein Cyclin D1, an essential regulator of G1 to S phase progression, is tightly associated, and aberrantly expressed in numerous human cancers [31] including human lung tumors, and several other types of human cancer [32]. Cyclin D1 is frequently overexpressed in various forms of cancer including nonsmall cell lung carcinoma (NSCLC) [33] and decrease in the level of expression of Cyclin D1 inhibits growth and reverses the transformed phenotype of human esophageal cancer cells [34]. Phosphorylation of the retinoblastoma $(\mathrm{Rb})$ protein during the $\mathrm{G} 1 / \mathrm{S}$ transition of the cell cycle appears to be initiated by Cyclin D/CDK4 and from this study we believe that protocatechualdehyde exerts its effect by cell cycle 
A.

GADD45 siRNA

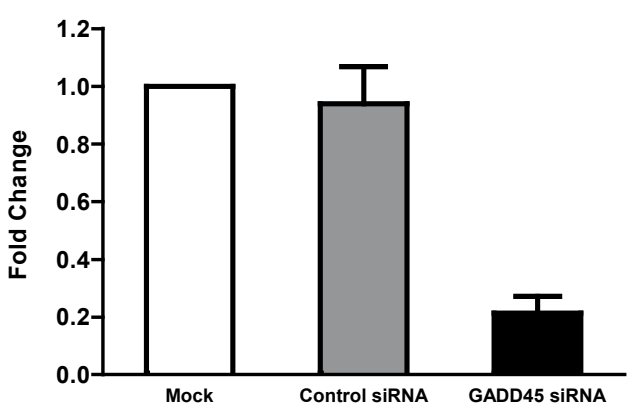

GADD153 siRNA

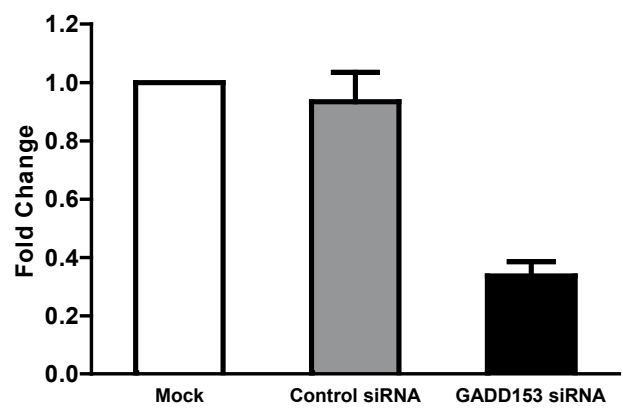

B.

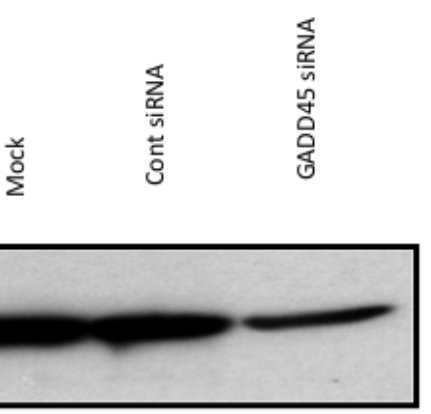

GADD45

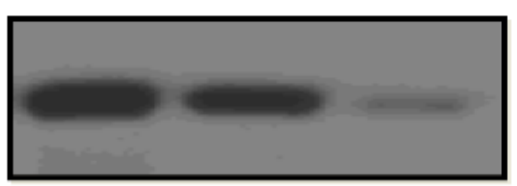

GADD153

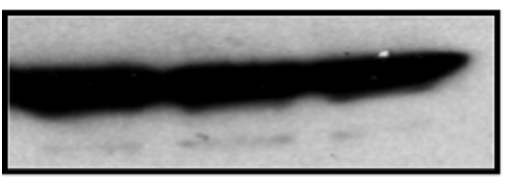

GAPDH

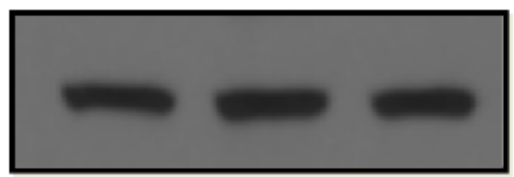

GAPDH

C.

24h

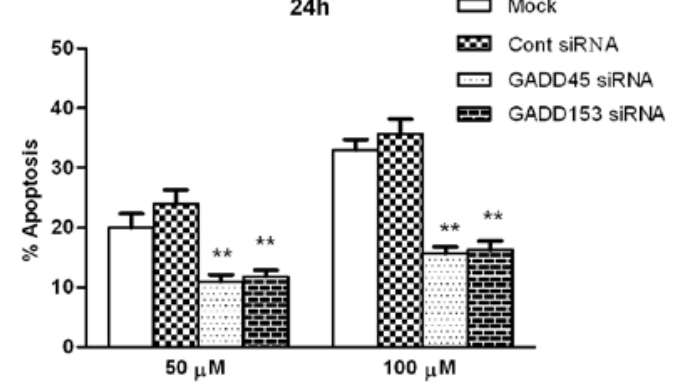

48h

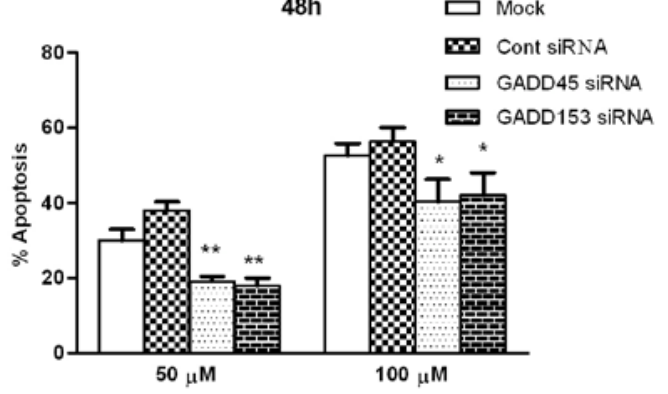

Figure 6: Protocatechualdehyde on GADD45 and 153 knockdown: PC-9 cells were transfected with Lipofectamine with GADD45, GADD153 siRNAs, control siRNAs or no siRNA. Controls for viability included cells mock-transfected with no siRNA or cells transfected with control siRNA. Twenty-four hours after transfection, cells were treated with vehicle or 50 or $100 \mu \mathrm{M}$ protocatechualdehyde for $24 \mathrm{~h}$. (A) The amounts of GADD45 and GADD153 mRNA with the mean of three separate experiments done in triplicate are expressed as mean \pm S.D. Expression level of genes normalized to GAPDH of mock was considered as 1 (B) followed by Western blotting with GAPDH as loading control. Three independent experiments produced similar results. (C) In a separate experiment, 24 hours after transfection, cells treated with vehicle, 50 or $100 \mu \mathrm{M}$ protocatechualdehyde were evaluated for extent of apoptosis, measured by DAPI staining at 24 and $48 \mathrm{~h}$. Bars represent mean \pm S.D. of two independent experiments performed in triplicate. ${ }^{*} \mathrm{p}<0.05,{ }^{* *} \mathrm{p}<0.01$. 
arrest in G1 phase in PC-9 cells by reducing the expression of Cyclin $\mathrm{D} 1$ and $C D K 4 / 6$ genes. Also the expression of CDK2 is decreased, demonstrating the importance of $C D K 2$ in the regulation of the cell cycle G1 checkpoint [35]. CDK inhibitor such as $\mathrm{p}^{21}$ is found associated with multiple Cyclin-CDK complexes, phosphorylated $\mathrm{p}^{21}$ binds simultaneously to both cyclin and CDKs and cyclin/CDK complexes are regulated by $\mathrm{p}^{21}[23]$. Indeed, $\mathrm{p}^{21}$ is a potent $\mathrm{CDK}$ inhibitor and displays selectivity for G1, and over-expression of $\mathrm{p}^{21}$ arrest cells in the G1 phase of the cell cycle [36,37]. Protocatechualdehyde reportedly affects cell proliferation and apoptosis in human colorectal cancer cells and define potential mechanisms by which protocatechualdehyde mediate growth arrest and apoptosis of cancer cells. Protocatechualdehyde decreases Cyclin D1 expression in protein and mRNA level and suppress luciferase activity of Cyclin D1 promoter, indicating transcriptional downregulation of cyclin D1 gene in human colorectal cancer cells. It was recently reported that suppressed cell proliferation by G1 arrest and induced apoptosis in human colorectal cancer cells [16] and the effect may mediated by apoptosis through upregulation of $\mathrm{p}^{21}$, in view of the fact that upregulation $\mathrm{p}^{21}$ may promote apoptosis. We hypothesized that protocatechualdehyde inhibited the growth of PC-9 cells and induced G1/S arrest of the cell cycle by upregulation of $p^{21}$ expression. Another member of the CDK inhibitor family $\mathrm{p}^{27 /}$ Kip1 binding to Cyclin E-CDK2 complexes and the binding dependent phosphorylation of $\mathrm{p}^{27}$ is involved in the transition of G1 to $S$ phase resulting in tumor suppression [38,39]. Earlier studies present strong evidence that the lack of functional $\mathrm{p}^{27}$ has a profound effect on tumorigenesis and is a major factor in the development of human tumors [40-43]. Up-regulated $p^{27}$ protein activity in PC-9 cells treated with protocatechualdehyde signifies that the $p^{27}$ gene upregulation is associated with cancer preventive activity [23].

To explore the possible association between GADD45 and GADD153 genes with apoptosis in PC-9 cells treated with protocatechualdehyde, we examined the knockdown of GADD45 and GADD153 gene expressions by siRNA in PC-9 cells. However, no significant change in the expression of cell-cycle regulating gene including $p^{21}, p^{27}$, cyclin $D 1, C D K 2, C D K 4$, and CDK6 were observed. From our result, the observed G1/S cell-cycle arrest by protocatechualdehyde in PC-9 cells may be associated with the variation of cell-cycle regulators by protocatechualdehyde. A significant observation in this study is that, expression of GADD45 and GADD153 genes in both $\mathrm{p}^{53}$ mutated PC-9 cells and $\mathrm{p}^{53}$ wild type A549 cells was up-regulated by treatment with protocatechualdehyde, indicating that $\mathrm{p}^{53}$ protein does not have direct stimulatory effect on expression of GADD45 and GADD153. The present study was designed to determine whether protocatechualdehyde increased expression of the gene GADD 45 and GADD153, which are induced by genotoxic stress through $\mathrm{p}^{53}$-dependent and -independent pathways. GADD45 and GADD153 gene expressions are induced by deoxycholate in both HCT-116 colonocytes with wild type $\mathrm{p}^{53}$ and $\mathrm{p}^{53}$ mutant HCT-15 colonocytes [44]. GADD proteins have been shown to inhibit proliferation and stimulate DNA repair and/or apoptosis [45]. The induced effect of protocatechualdehyde on these gene expressions in PC-9 and A549 cells would be independent of $\mathrm{p}^{53}$ as it was reported with other genotoxic agents. One observation reported by several researchers involves correlation between upregulation of GADD45 and GADD153 and apoptotic induction in actively dividing cells [4648]. Earlier study indicates that the induction of apoptosis in mice exposed to hyperoxia was associated with the upregulation of GADD45 and GADD153 gene expressions [45]. Natural products like curcumin is reported to induce DNA damage, apoptosis by GADD153 gene in human colon cancer cell lines [48].
In this study, we show that treatment with siRNAs inhibits the expression of GADD45 and GADD153 in PC-9 cells and induce apoptosis, suggesting significant role of GADD gene family in the mechanisms of cancer prevention. Protocatechualdehyde is also one of the active components of cardamom, popular dietary spice [49]. Data from earlier studies indicate that regular consumption of medicinal herbs like cardamom enhances activities like fibrinolysis, antioxidant [50] and Natural killer (NK) cell [51] in humans. Therefore, the daily consumption of cardamom will contribute to protocatechualdehyde and protect against the risk of cancer. GADD45 and GADD153 are new targets for protocatechualdehyde in lung cancer, and may be used in lung cancer prevention and treatment in humans.

\section{Acknowledgments}

This work was supported by Manipal University, Manipal India

\section{Reference}

1. Rosemary Siafakas A, Richardson DR (2009) Growth arrest and DNA damage-45 alpha (GADD45alpha). Int J Biochem Cell Biol 41: 986-989.

2. Hildesheim J, Fornace AJ Jr (2002) Gadd45a: an elusive yet attractive candidate gene in pancreatic cancer. Clin Cancer Res 8: 2475-2479.

3. Siegel R, Naishadham D, Jemal A (2013) Cancer statistics, 2013. CA Cancer J Clin 63: 11-30.

4. Landis MD, Lehmann BD, Pietenpol JA, Chang JC (2013) Patient-derived breast tumor xenografts facilitating personalized cancer therapy. Breas Cancer Res 15: 201.

5. Toh CK, Gao F, Lim WT, Leong SS, Fong KW, et al. (2006) Never-smokers with lung cancer: epidemiologic evidence of a distinct disease entity. J Clin Oncol 24: 2245-2251.

6. Hecht SS, Kassie F, Hatsukami DK (2009) Chemoprevention of lung carcinogenesis in addicted smokers and ex-smokers. Nat Rev Cancer 9: 476488.

7. Ganesh B, Sushama S, Monika S, Suvarna P (2011) A case-control study of risk factors for lung cancer in Mumbai, India. Asian Pac J Cancer Prev 12 357-362.

8. Keith RL (2009) Chemoprevention of lung cancer. Proc Am Thorac Soc 6: 187 193.

9. Bae JS, Ahn SJ, Yim H, Jang KH, Jin HK (2005) Prevention of intraperitoneal adhesions and abscesses by polysaccharides isolated from Phellinus spp in a rat peritonitis model. Ann Surg 241: 534-540.

10. Bae JS, Jang KH, Park SC, Jin HK (2005) Promotion of dermal wound healing by polysaccharides isolated from Phellinus gilvus in rats. J Vet Med Sci 67 111-114.

11. Chang ZQ, Hwang MH, Rhee MH, Kim KS, Kim JC, et al. (2008) The in vitro anti-platelet, antioxidant and cellular immunity activity of phellinus gilvus fractional extracts. World J Microbiol Biotechnol 24: 181-187.

12. Chang ZQ, Gebru E, Lee SP, Rhee MH, Kim JC, et al. (2011) In vitro antioxidant and anti-inflammatory activities of protocatechualdehyde isolated from Phellinus gilvus. J Nutr Sci Vitaminol (Tokyo) 57: 118-122.

13. Jang BS, Kim JC, Bae JS, Rhee MH, Jang KH, et al. (2004) Extracts of Phellinus gilvus and Phellinus baumii inhibit pulmonary inflammation induced by lipopolysaccharide in rats. Biotechnol Lett 26: 31-33.

14. Kuang P, Tao Y, Tian Y (1996) Radix salviae miltiorrhizae treatment results in decreased lipid peroxidation in reperfusion injury. J Tradit Chin Med 16: 138 142

15. Liu GT, Zhang TM, Wang BE, Wang YW (1992) Protective action of seven natural phenolic compounds against peroxidative damage to biomembranes. Biochem Pharmacol 43: 147-152.

16. Jeong JB, Lee SH (2013) Protocatechualdehyde possesses anti-cancer activity through downregulating cyclin $\mathrm{d} 1$ and hdac2 in human colorectal cancer cells. Biochem Biophys Res Commun 430: 381-386.

17. Nishimura M, Umeda M, Kusanagi A, Urakabe R, Yukimatsu K, et al. (1981) Antiproliferative activity of protocatechualdehyde on Chinese hamster cells grown in culture. Gann 72: 868-879. 
Citation: Patra S, Mascarenhas R, Maliyakkal N, Aranjani JM (2013) Protocatechualdehyde Induces Apoptosis in Human Non-Small-Cell Lung Cancer Cells by up Regulation of Growth Arrest and DNA Damage-Inducible (GADD) Genes. Mol Biol 2: 113. doi:10.4172/2168-9547.1000113

Page 9 of 9

18. Wang Y, Hasuma T, Yano Y, Morishima Y, Matsui-Yuasa I, et al. (2001) Induction of apoptosis in CTLL-2 cells by protocatechualdehyde. Anticancer Res 21: 1095-1101.

19. Wang Y, Zhu Z, Hasuma T, Yano Y, Morishima Y, et al. (2002) Modulation of ornithine decarboxylase activity and mitogen-activated protein kinases in protocatechualdehyde-induced apoptosis of CTLL-2 cells. Anticancer Res 22 : 3389-3394.

20. Kim KJ, Kim MA, Jung JH (2008) Antitumor and antioxidant activity of protocatechualdehyde produced from Streptomyces lincolnensis M-20. Arch Pharm Res 31: 1572-1577.

21. Prachayasittikul $S$, Buraparuangsang $P$, Worachartcheewan $A$, IsarankuraNa-Ayudhya C, Ruchirawat S, et al. (2008) Antimicrobial and antioxidative activities of bioactive constituents from Hydnophytum formicarum Jack. Molecules 13: 904-921.

22. Xing YL, Zhou Z, Agula, Zhong ZY, Ma YJ, et al. (2012) Protocatechuic aldehyde inhibits lipopolysaccharide-induced human umbilical vein endothelial cell apoptosis via regulation of caspase-3. Phytother Res 26: 1334-1341.

23. Meeran SM, Katiyar SK (2008) Cell cycle control as a basis for cancer chemoprevention through dietary agents. Front Biosci 13: 2191-2202.

24. Sánchez I, Dynlacht BD (2005) New insights into cyclins, CDKs, and cell cycle control. Semin Cell Dev Biol 16: 311-321.

25. Sundaram M, Patra S, Maniarasu G (2012) Antitumor activity of ethanol extract of Gracilaria edulis (Gmelin) Silva on Ehrlich ascites carcinoma-bearing mice. Zhong Xi Yi Jie He Xue Bao 10: 430-435.

26. Arredondo J, Chernyavsky AI, Marubio LM, Beaudet AL, Jolkovsky DL, et al. (2005) Receptor-mediated tobacco toxicity: regulation of gene expression through alpha3beta2 nicotinic receptor in oral epithelial cells. Am J Pathol 166 597-613.

27. Sielecki TM, Boylan JF, Benfield PA, Trainor GL (2000) Cyclin-dependent kinase inhibitors: useful targets in cell cycle regulation. J Med Chem 43: 1-18.

28. Moon CY, Ku CR, Cho YH, Lee EJ (2012) Protocatechuic aldehyde inhibits migration and proliferation of vascular smooth muscle cells and intravascular thrombosis. Biochem Biophys Res Commun 423: 116-121.

29. Chan FK, Zhang J, Cheng L, Shapiro DN, Winoto A (1995) Identification of human and mouse p19, a novel CDK4 and CDK6 inhibitor with homology to p16ink4. Mol Cell Biol 15: 2682-2688.

30. Vermeulen K, Van Bockstaele DR, Berneman ZN (2003) The cell cycle: a review of regulation, deregulation and therapeutic targets in cancer. Cell Prolif 36: 131-149.

31. Saha A, Halder S, Upadhyay SK, Lu J, Kumar P, et al. (2011) Epstein-Bar virus nuclear antigen $3 \mathrm{C}$ facilitates $\mathrm{G} 1-\mathrm{S}$ transition by stabilizing and enhancing the function of cyclin D1. PLoS Pathog 7: e1001275.

32. Betticher DC, Heighway J, Hasleton PS, Altermatt HJ, Ryder WD, et al. (1996) Prognostic significance of CCND1 (cyclin D1) overexpression in primary resected non-small-cell lung cancer. Br J Cancer 73: 294-300.

33. Schauer IE, Siriwardana S, Langan TA, Sclafani RA (1994) Cyclin D1 overexpression vs. retinoblastoma inactivation: implications for growth contro evasion in non-small cell and small cell lung cancer. Proc Natl Acad Sci U S A 91: 7827-7831.

34. Zhou P, Jiang W, Zhang YJ, Kahn SM, Schieren I, et al. (1995) Antisense to cyclin D1 inhibits growth and reverses the transformed phenotype of human esophageal cancer cells. Oncogene 11: 571-580.

35. van den Heuvel S, Harlow E (1993) Distinct roles for cyclin-dependent kinases in cell cycle control. Science 262: 2050-2054.
36. Harper JW, Elledge SJ, Keyomarsi K, Dynlacht B, Tsai LH, et al. (1995) Inhibition of cyclin-dependent kinases by p21. Mol Biol Cell 6: 387-400.

37. LeBlanc DJ, Hassell FP (1976) Transformation of Streptococcus sanguis Challis by plasmid deoxyribonucleic acid from Streptococcus faecalis. J Bacteriol 128: 347-355.

38. Abukhdeir AM, Park BH (2008) P21 and p27: roles in carcinogenesis and drug resistance. Expert Rev Mol Med 10: e19.

39. Srivastava RK, Chen Q, Siddiqui I, Sarva K, Shankar S (2007) Linkage of curcumin-induced cell cycle arrest and apoptosis by cyclin-dependent kinase inhibitor p21(/WAF1/CIP1). Cell Cycle 6: 2953-2961.

40. Fero ML, Randel E, Gurley KE, Roberts JM, Kemp CJ (1998) The murine gene p27Kip1 is haplo-insufficient for tumour suppression. Nature 396: 177-180.

41. Kiyokawa H, Kineman RD, Manova-Todorova KO, Soares VC, Hoffman ES et al. (1996) Enhanced growth of mice lacking the cyclin-dependent kinase inhibitor function of p27(Kip1). Cell 85: 721-732.

42. Nakayama K, Ishida N, Shirane M, Inomata A, Inoue T, et al. (1996) Mice lacking p27(Kip1) display increased body size, multiple organ hyperplasia retinal dysplasia, and pituitary tumors. Cell $85: 707-720$.

43. Park MS, Rosai J, Nguyen HT, Capodieci P, Cordon-Cardo C, et al. (1999) p27 and $\mathrm{Rb}$ are on overlapping pathways suppressing tumorigenesis in mice. Proc Natl Acad Sci U S A 96: 6382-6387.

44. Scott DW, Mutamba S, Hopkins RG, Loo G (2005) Increased GADD gene expression in human colon epithelial cells exposed to deoxycholate. J Cell Physiol 202: 295-303.

45. O'Reilly MA, Staversky RJ, Watkins RH, Maniscalco WM, Keng PC (2000) p53-independent induction of GADD45 and GADD153 in mouse lungs exposed to hyperoxia. Am J Physiol Lung Cell Mol Physiol 278: L552-559.

46. Powolny A, Takahashi K, Hopkins RG, Loo G (2003) Induction of GADD gene expression by phenethylisothiocyanate in human colon adenocarcinoma cells. J Cell Biochem 90: 1128-1139.

47. Satoh T, Toyoda M, Hoshino H, Monden T, Yamada M, et al. (2002) Activation of peroxisome proliferator-activated receptor-gamma stimulates the growth arrest and DNA-damage inducible 153 gene in non-small cell lung carcinoma cells. Oncogene 21: 2171-2180.

48. Scott DW, Loo G (2004) Curcumin-induced GADD153 gene up-regulation in human colon cancer cells. Carcinogenesis 25: 2155-2164.

49. Kikuzaki H, Kawai Y, Nakatani N (2001) 1,1-Diphenyl-2-picrylhydrazyl radicalscavenging active compounds from greater cardamom (Amomum subulatum Roxb.). J Nutr Sci Vitaminol (Tokyo) 47: 167-171.

50. Verma SK, Jain V, Katewa SS (2009) Blood pressure lowering, fibrinolysis enhancing and antioxidant activities of cardamom (Elettaria cardamomum). Indian J Biochem Biophys 46: 503-506.

51. Bhat J, Damle A, Vaishnav PP, Albers R, Joshi M, et al. (2010) In vivo enhancement of natural killer cell activity through tea fortified with Ayurvedic herbs. Phytother Res 24: 129-135. 